\title{
7-0-descarbamoyl-7-hydroxygeldanamycin, a minor component from the gdmN disruption mutant of Streptomyces hygroscopicus 17997
}

\author{
Siyang $\mathrm{Ni}^{1,2}$, Linzhuan $\mathrm{Wu}^{1,2}$, Hongyuan Wang ${ }^{1,2}$, Yiguang Wang ${ }^{1,2}$, Weiqing $\mathrm{He}^{1,2}$, Yonghai $\mathrm{Li}^{1,2}$, \\ Changhong Jia ${ }^{1,2}$, Shufen $\mathrm{Li}^{1,2}$ and Yucheng Wang ${ }^{2}$
}

The Journal of Antibiotics (2010) 63, 623-625; doi:10.1038/ja.2010.96; published online 4 August 2010

Keywords: bioconversion; gdmN; geldanamycin biosynthesis; 7-O-descarbamoyl-7-hydroxygeldanamycin; Streptomyces hygroscopicus 17997

Geldanamycin (GDM) is a 19-membered macrocyclic lactam and is related to ansamycin antibiotics. GDM binds to heat shock protein 90 , inhibiting its chaperone activity. ${ }^{1}$ GDM and its derivatives have the potential to serve as chemotherapeutic agents in cancer and virusinfected diseases. ${ }^{2}$ A clear understanding of GDM biosynthesis should help us to create novel GDM analogs with optimal properties by genetic manipulation of its biosynthetic pathway.

The biosynthetic gene cluster of GDM, including a set of type-I polyketide synthase (PKS) genes, a set of post-PKS tailoring genes and a separate set of genes for biosynthesis of 3-amino-5-hydroxybenzoic acid, the starter unit for GDM biosynthesis, had been cloned, sequenced and analyzed from several streptomycetes independently. ${ }^{3-5}$ The post-PKS tailoring genes, such as $g d m N$ (encoding the carbamoyltransferase for 7-O-carbamoylation), $g d m P$ (encoding the cytochrome P450 monooxygenase for C-4,5 oxidation) and $g d m M$ (encoding the FAD-binding monooxygenase for C-21 hydroxylation), had been disrupted, respectively, in Streptomyces hygroscopicus 17997, S. hygroscopicus subsp. duamyceticus JCM4427 or other GDM producer(s), to confirm their biological functions in GDM biosynthesis. ${ }^{6-8}$ As a result, a brief post-PKS tailoring process of GDM biosynthesis was proposed (Figure 1, thick arrows). ${ }^{6}$

The gels (identical to $g d m N$ ) disruption mutant of $S$. hygroscopicus subsp. duamyceticus JCM4427 produced 4,5-dihydro-7-O-descarbamoyl-7-hydroxygeldanamycin (CT-1-7) as major component. ${ }^{6}$ The $g d m N$ disruption mutant of $S$. hygroscopicus 17997 produced, besides CT-1-7, 4,5-dihydro-7-O-descarbamoyl-7-hydroxy-19-O-glycylgeldanamycin (CT-1-1), which is a novel GDM analog. ${ }^{9}$

To examine whether there are other undiscovered GDM analogs in the $g d m N$ disruption mutant of $S$. hygroscopicus 17997, a time-course monitoring of its fermentation culture was conducted. The fermentation supernatants at different times $(36,60,84,108 \mathrm{~h}$, and so on) were extracted with equal volumes of ethyl acetate (EtOAc). The organic layers were concentrated, then subjected to silica-gel TLC (developed with a mobile phase of EtOAc/ $\mathrm{CH}_{2} \mathrm{Cl}_{2} /$ hexane/methanol, 9:6:6:1, v/v) and then alkaline color reaction for a preliminary discrimination of GDM analogs. ${ }^{10}$ A weak purple band appeared above the blue band of CT-1-7, which was supposed to be a novel GDM analog (at $84 \mathrm{~h}$, Figure 2).

Compounds corresponding to the weak purple band of alkaline treatment were eluted out with EtOAc from silica-gel TLC. A major peak appeared by HPLC analysis, with its retention time being very close to that of CT-1-7, and its UV spectrum profile similar to that of CT-1-7 and very similar to that of GDM (see Supplementary Figure S1). The peak contained a major compound with a molecular weight of $540.5 \mathrm{Da}\left([\mathrm{M}+\mathrm{Na}]^{+}\right)$, which is two units less than that of CT-1-7 $\left(542.4 \mathrm{Da},[\mathrm{M}+\mathrm{Na}]^{+}\right)$, as analyzed by liquid chromatography-ESI(+)MS. Based on these data, we suggested the chemical structure of the major compound as 7-O-descarbamoyl-7-hydroxygeldanamycin (designated as CT-1-7x), with a molecular formula of $\mathrm{C}_{28} \mathrm{H}_{39} \mathrm{O}_{8} \mathrm{~N}_{1}$.

CT-1-7x was then purified for structural elucidation. An equal volume of EtOAc was used to extract the fermentation supernatant (about 10l) of $g d m N$ disruption mutant of S. hygroscopicus 17997 (culture time $84 \mathrm{~h}$ ), then dried to a crude solid (about $3.042 \mathrm{~g}$ ) by rotary evaporation at $37^{\circ} \mathrm{C}$. It was then fractionated by silica-gel column chromatography. The pool containing CT-1-7x (eluted by petroleum ether-EtOAc, 75:25, v/v) was dried $(30.8 \mathrm{mg}$ ) and re-dissolved in methanol for preparative Sephadex LH-20 $(\varphi 1.8 \mathrm{~cm} \times 150 \mathrm{~cm})$ fractionation, yielding the refined preparation

${ }^{1}$ Key Laboratory of Biotechnology of Antibiotics, Ministry of Health, Beijing, China and ${ }^{2}$ Institute of Medicinal Biotechnology, Peking Union Medical College and Chinese Academy Medical Sciences, Beijing, China

Correspondence: Professor L Wu or Professor Y Wang, Institute of Medicinal Biotechnology, Peking Union Medical College and Chinese Academy Medical Sciences, Tiantan Xili, Beijing 100050, China.

E-mails: wulinzhuan@yahoo.com.cn or wyc9999@126.com

Received 19 April 2010; revised 7 July 2010; accepted 9 July 2010; published online 4 August 2010 


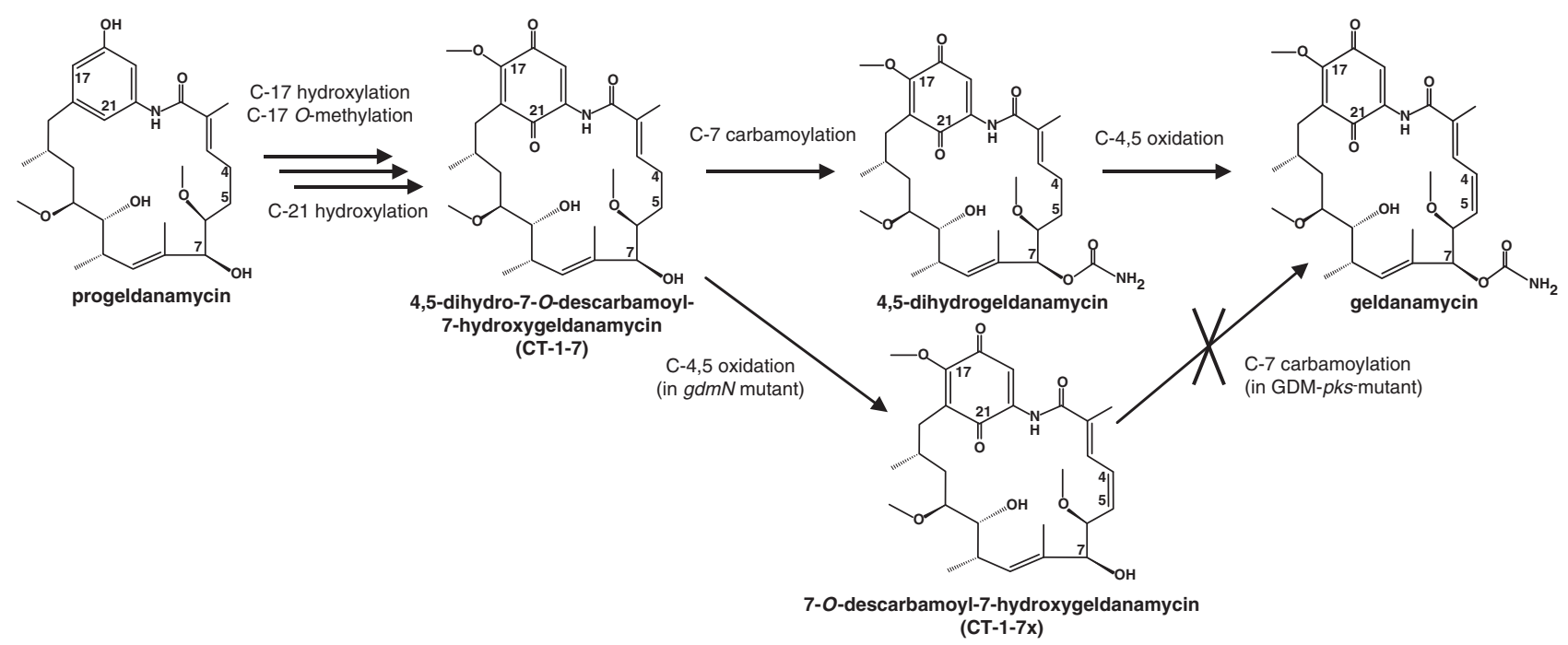

Figure 1 The post-polyketide synthase tailoring process of geldanamycin biosynthesis.

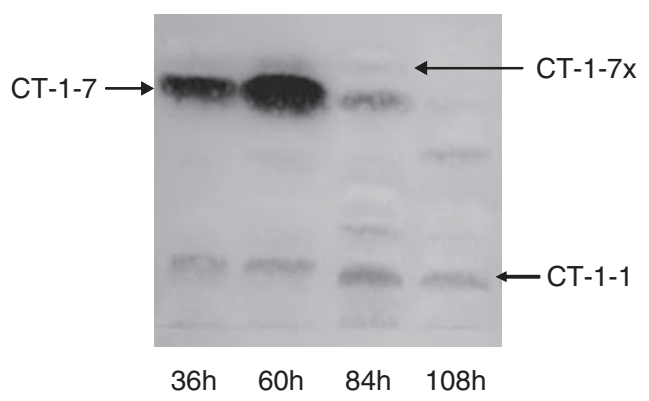

Figure 2 Silica-gel TLC (GF254) of the ethyl acetate (EtOAc) extract of gdmN disruption mutant of Streptomyces hygroscopicus 17997 at different fermentation times (after the color reaction by $2 \mathrm{~mol}$ per liter $\mathrm{NaOH}$ ). The $g d m N$ disruption mutant of $S$. hygroscopicus 17997 was grown at $28^{\circ} \mathrm{C}$ for 7-10 days on MY agar (yeast extract $0.4 \%$, malt extract $1.0 \%$, glucose $0.4 \%$, agar power $1.5 \%$ ) plates (apramycin, $50 \mu \mathrm{g} \mathrm{ml} \mathrm{l}^{-1}$ ) for sporulation, then inoculated into the fermentation medium (starch $2 \%$, cotton seed power $0.5 \%$, glucose $0.5 \%$, corn steep liquor $1.0 \%$, yeast powder $0.5 \%$, $\mathrm{CaCO}_{3} 0.2 \%$ ) for shaking (200 r.p.m.) at $28{ }^{\circ} \mathrm{C}$ for different times, and the culture supernatants were extracted with EtOAc. CT-1-7x appeared at a culture time of $84 \mathrm{~h}$ with a production level of about $10 \mathrm{mgl}^{-1}$.

(17.9 mg). The refined preparation was used for preparative HPLC (Shimadzu LC-10ATVp, Shimadzu International Trading (Shanghai) Co., Ltd, Beijing, China; Agilent ZorBax SB-C18, Agilent Technologies Co. Ltd (China), Beijing, China, $5 \mu \mathrm{m}, \varphi 9.4 \mathrm{~mm} \times 250 \mathrm{~mm}$, methanol/

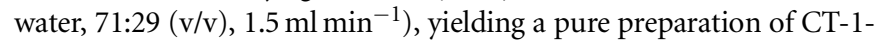
$7 \mathrm{x}(10.7 \mathrm{mg}$, purity $\geqslant 97 \%)$. The pure preparation, an amorphous yellow powder, was used for ${ }^{1} \mathrm{H}$ - and ${ }^{13} \mathrm{C}-\mathrm{NMR}$ analyses.

The ${ }^{13} \mathrm{C}-\mathrm{NMR}$ and DEPT spectra displayed 28 carbon signals, including 7 methyls, 2 methylenes, 11 methines and 8 quaternary carbons. The ${ }^{13} \mathrm{C}-\mathrm{NMR}$ of CT-1-7x showed strong similarities to that of CT-1-7 except for C-4,5. The carbon signals of $\mathrm{CH}_{2}-4\left(\delta_{\mathrm{C}} 23.84\right)$ and $\mathrm{CH}_{2}-5\left(\delta_{\mathrm{C}} 29.19\right)$ in CT-1-7 were absent, while two additional olefinic methyl signals at $\delta_{\mathrm{C}} 131.163$ and 127.340 emerged in the ${ }^{13} \mathrm{C}$ NMR of CT-1-7x. The hydrogen signals of $\mathrm{CH}_{2}-4\left(\delta_{\mathrm{H}} 2.24 / 2.43\right)$ and $\mathrm{CH}_{2}-5\left(\delta_{\mathrm{H}} 1.74 / 1.89\right)$ of CT-1-7 disappeared in CT-1-7x, while two additional hydrogen signals of $\mathrm{CH}-\left(\delta_{\mathrm{H}} 6.590,6.075\right)$ appeared in the ${ }^{1} \mathrm{H}-\mathrm{NMR}$ of CT-1-7x. The two newly appeared olefinic methyl signals (CH-4 and $\mathrm{CH}-5)$ in $\mathrm{CT}-1-7 \mathrm{x}$ were also confirmed by the DEPT
Table 1 NMR data of CT-1-7 $x^{a}$

\begin{tabular}{|c|c|c|c|c|}
\hline $\begin{array}{l}\text { Carbon } \\
\text { no. }\end{array}$ & $\delta_{H}$ Mult jo & $\delta_{C}$ & $\cos Y$ & $H M B C$ \\
\hline 1 & & 168.268 & & \\
\hline 2 & & 136.977 & & $\mathrm{H}-2-\mathrm{CH}_{3}, 4,5$ \\
\hline 3 & $6.929,1 \mathrm{H}, \mathrm{d}, 12$ & 138.488 & $\mathrm{H}-4,5,2-\mathrm{CH}_{3}$ & $\mathrm{H}-2-\mathrm{CH}_{3}, 4,5$ \\
\hline 4 & $6.590,1 \mathrm{H}, \mathrm{t}, 11.4$ & 131.163 & $\mathrm{H}-3,5$ & $\mathrm{H}-3,5,6$ \\
\hline 5 & $6.075,1 \mathrm{H}, \mathrm{t}, 10.2$ & 127.340 & $\mathrm{H}-4,6$ & $\mathrm{H}-3,4,6$ \\
\hline 6 & $3.378,1 \mathrm{H}, \mathrm{t}$, over & 81.121 & $H-5,7$ & $\mathrm{H}-4,5,7,6-\mathrm{OCH}_{3}$ \\
\hline 7 & $4.225,1 \mathrm{H}, \mathrm{d}, 9.6$ & 80.629 & $\mathrm{H}-6,9$ & $\mathrm{H}-6-\mathrm{OCH}_{3}, 8-\mathrm{CH}_{3}$, S \\
\hline 8 & & 134.554 & & $\mathrm{H}-7,8-\mathrm{CH}_{3}, 9$ \\
\hline 9 & $5.650,1 \mathrm{H}, \mathrm{d}, 10.2$ & 125.589 & $\mathrm{H}-7,10$ & $\mathrm{H}-7,8-\mathrm{CH}_{3}, 10$ \\
\hline 10 & $2.845,1 \mathrm{H}, \mathrm{m}$, over & 32.013 & $\mathrm{H}-9,10-\mathrm{CH}_{3}, 11$ & $\mathrm{H}-9,10-\mathrm{CH}_{3}, 11$ \\
\hline 11 & $3.510,1 \mathrm{H}, \mathrm{t}$ & 72.948 & $\mathrm{H}-10,12$ & $\mathrm{H}-10,10-\mathrm{CH}_{3}, 12$ \\
\hline 12 & $4.024,1 \mathrm{H}, \mathrm{d}$ & 80.826 & $\mathrm{H}-11,13$ & $\mathrm{H}-11,12-\mathrm{OCH}_{3}, 13$ \\
\hline 13 & $1.746,2 \mathrm{H}, \mathrm{m}$, over & 34.138 & & $\mathrm{H}-12,14$ \\
\hline 14 & $1.806, \mathrm{H}, \mathrm{m}$, over & 27.689 & $\mathrm{H}-13,15$ & $\mathrm{H}-13,15$ \\
\hline 15 & $2.490,2 \mathrm{H}, \mathrm{m}$ & 32.791 & & $\mathrm{H}-14,14-\mathrm{CH}_{3}$, \\
\hline 16 & & 127.684 & & $\mathrm{H}-15$ \\
\hline 17 & & 156.945 & & $\mathrm{H}-15,17-\mathrm{OCH}_{3}$ \\
\hline 18 & & 184.198 & & $\mathrm{H}-19$ \\
\hline 19 & & 111.671 & & $\mathrm{H}-\mathrm{NH}$ \\
\hline 20 & & 138.144 & & $\mathrm{H}-19$ \\
\hline 21 & & 184.885 & & $\mathrm{H}-15,19, \mathrm{NH}$ \\
\hline $2-\mathrm{CH}_{3}$ & $2.070,3 \mathrm{H}, \mathrm{s}$ & 12.552 & & $\mathrm{H}-3$ \\
\hline $6-\mathrm{OCH}_{3}$ & $3.335,3 \mathrm{H}, \mathrm{s}$ & 56.588 & & $\mathrm{H}-6$ \\
\hline $8-\mathrm{CH}_{3}$ & $0.985,3 \mathrm{H}, \mathrm{d}, 6.6$ & 11.937 & $\mathrm{H}-9$ & $\mathrm{H}-7,9$ \\
\hline $10-\mathrm{CH}_{3}$ & $1.294,3 \mathrm{H}, \mathrm{t}, 7.2$ & 14.218 & $\mathrm{H}-10$ & $\mathrm{H}-10$ \\
\hline $12-\mathrm{OCH}_{3}$ & $3.392,3 \mathrm{H}, \mathrm{s}$ & 56.801 & & $\mathrm{H}-12$ \\
\hline $14-\mathrm{CH}_{3}$ & $1.022,3 \mathrm{H}, \mathrm{d}, 6.6$ & 23.105 & $\mathrm{H}-14$ & $\mathrm{H}-14,13,15$ \\
\hline $17-\mathrm{OCH}_{3}$ & $4.161,3 \mathrm{H}, \mathrm{s}$, over & 61.709 & & $\mathrm{H}-19-\mathrm{OCOCH}{ }_{2} \mathrm{NH}_{2}$ \\
\hline $\mathrm{NH}$ & 8.713 & & & \\
\hline
\end{tabular}

${ }^{\mathrm{a} 1 \mathrm{H}}$ - and ${ }^{13} \mathrm{C}$-NMR spectra were obtained on Bruker Advance $600 \mathrm{MHz}$ (Bruker BioSpin, AG Ltd. (PR China), Beijing, China) with tetramethylsilane (TMS) as internal standard, 2D NMR

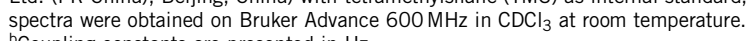
bCoupling constants are presented in $\mathrm{Hz}$.

spectra of CT-1-7x. The NMR chemical shifts were assigned completely for CT-1-7x from HSQC, COSY and HMBC (Table 1). Thus, the chemical structure of CT-1-7x was determined to be the C-4,5 olefinic form of CT-1-7, that is, 7-O-descarbamoyl-7-hydroxygeldanamycin. 


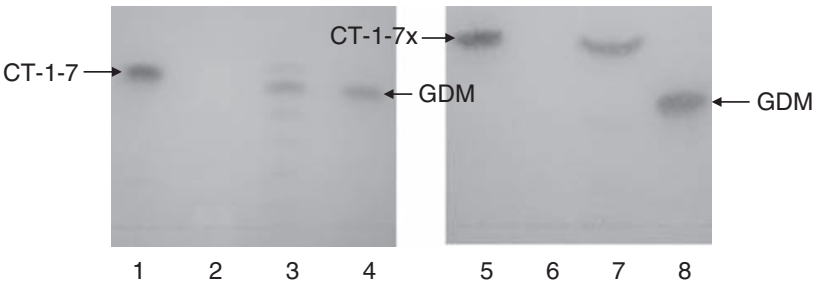

Figure 3 Bioconversion of CT-1-7 and CT-1-7x. CT-1-7 was converted to geldanamycin (GDM) without difficulty by GDM-pks-, while CT-1-7x failed to be converted to GDM by GDM-pks-. Left: 1, CT-1-7; 2, GDM-pks-; 3, CT-17+GDM-pks-; 4, GDM. Right: 5, CT-1-7x; 6, GDM-pks-; 7, CT-1-7x+GDMpks-; 8, GDM. For bioconversion, flasks of $250 \mathrm{ml}$, each containing $40 \mathrm{ml}$ fermentation medium (starch $2 \%$, glucose $0.5 \%$, cottonseed cake power $0.5 \%$, corn steep liquor $1.0 \%$, yeast power $0.5 \%$ and $\mathrm{CaCO}_{3} 0.2 \%$ ) were inoculated with spores of GDM-pks-, shaken at $28{ }^{\circ} \mathrm{C}$ with 200 r.p.m. for $60 \mathrm{~h}$ and then treated with $4 \mathrm{mg}$ CT-1-7 or CT-1-7x (in $100 \mu \mathrm{l}$ ethyl acetate $(E t O A c)$ ) for each flask, and shaken for another $12 \mathrm{~h}$ (or for an even longer time of 24-48 h). The culture broth was extracted once with $40 \mathrm{ml}$ EtOAc, the organic phase was evaporated in vacuo, and the residue dissolved in $200 \mu \mathrm{l}$ EtOAc. About $10 \mu \mathrm{l}$ of each sample was used for silica-gel TLC and then alkaline color reaction to check whether GDM was produced.

CT-1-7x shared the same chemical structure as the compound designated as CP 144365, ${ }^{11}$ whose spectroscopic data and references, if any, were not disclosed.

Shin et al. ${ }^{7}$ proved that a cytochrome P450 monooxygenase encoded by $g d m P$ of the GDM biosynthetic gene cluster was involved in the formation of C-4,5 double bonds of GDM in the post-PKS tailoring process of GDM biosynthesis. The discovery of CT-1-7x from the $g d m N$ disruption mutant of $S$. hygroscopicus 17997 indicated that the cytochrome $\mathrm{P} 450$ monooxygenase encoded by $g d m P$ had a relaxed substrate specificity, which is common to enzymes for microbial secondary metabolite biosynthesis.

It seems that the carbamoyltransferase in the post-PKS tailoring process of GDM biosynthesis exhibited also a relaxed substrate specificity, as several GDM biosynthetic intermediates or their analogs with 7-O-carbamoylation, such as KOS-1806, reblastatin and 8demethylgeldanamycin, were discovered or isolated. ${ }^{12,13}$ To confirm whether CT-1-7x could be further 7-O-carbamoylated (producing GDM), a bioconversion experiment was conducted (Figure 3). Contrary to our expectation, incubation of CT-1-7x with GDM-pks ${ }^{-}, 8$ a GDM's PKS gene disruption mutant of S. hygroscopicus 17997 (it lost the ability to produce GDM, but still had a full complement of post-
PKS tailoring process genes), resulted in no production of GDM, while incubation of CT-1-7 (as the positive control) with GDM-pks resulted in the production of GDM as had been reported earlier by Hong et al. ${ }^{6}$ This result led us to conclude that the carbamoyltransferase in the post-PKS tailoring process of GDM biosynthesis showed a special substrate specificity, that is, the C-4,5 of its substrate(s) being single-bonded. Therefore, 7-O-carbamoylation must take place before $\mathrm{C}-4,5$ oxidation in the post-PKS tailoring process of GDM biosynthesis, but the two steps are not necessarily close to each other.

\section{ACKNOWLEDGEMENTS}

This work was supported by the National S\&T Major Special Project on Major New Drug Innovation (Item Numbers 2009ZX09501-008 and 2009ZX09301003-7-2).

1 Stebbins, C. E. et al. Crystal structure of an Hsp90-geldanamycin complex: targeting of a protein chaperone by an antitumor agent. Cell 89, 239-250 (1997).

2 Li, Y. H., Tao, P. Z., Liu, Y. Z. \& Jiang, J. D. Geldanamycin, a ligand of heat shock protein 90, inhibits the replication of herpes simplex virus type 1 in vitro. Antimicrob Agents Chemother. 48, 867-872 (2004).

3 Rascher, A. et al. Cloning and characterization of a gene cluster for geldanamycin production in Streptomyces hygroscopicus NRRL 3602. FEMS Microbiol. Lett. 218, 223-230 (2003).

4 Hong, Y. S. et al. in Book of Abstracts, 13th International Symposium on the Biology of Actinomycetes (ed. Kurtboke, I.) 33 (ISBA' 13, Melbourne, Australia, 2003).

5 Wang, Y.G. \& Gao, Q.J. Cloning of geldanamycin biosynthetic gene from Streptomyces hygroscopicus 17997. in Ninth International Symposium on the Genetics of Industrial Microorganisms, Gyeongju, Korea Abstract P2-46 (2002).

6 Hong, Y. S. et al. Inactivation of the carbamoyltransferase gene refines post-polyketide synthase modification steps in the biosynthesis of the antitumor agent geldanamycin. J. Am. Chem. Soc. 126, 11142-11143 (2004).

7 Shin, J. C. et al. Characterization of tailoring genes involved in the modification of geldanamycin polyketide in Streptomyces hygroscopicus JCM4427. J. Microbiol. Biotechnol. 18, 1101-1108 (2008).

8 He, W. Q., Liu, Y. Y., Sun, G. Z. \& Wang, Y. G. Roles of geldanamycin biosynthetic genes in Streptomyces hygroscopicus 17997. Chin. J. Biotech. 24, 1133-1139 (2008).

9 Li, Y. Y., He, W. Q., Wang, Y. G., Wang, Y. C. \& Shao, R. G. A new post-PKS modification process in the carbamoyltransferase gene inactivation strain of Streptomyces hygroscopicus 17997. J. Antibiot. 61, 347-355 (2008).

$10 \mathrm{Liu}, \mathrm{A}$. M. et al. A color reaction method for early preliminary discrimination of benzenic ansamycins [in Chinese]. Chin. J. Antibiot. 33, 403-406 (2008).

11 Miller, P. et al. Depletion of the erbB-2 gene product p185 by benzoquinoid ansamycins. Cancer Res. 54, 2724-2730 (1994).

12 Rascher, A., Hu, Z., Buchanan, G. O., Reid, R. \& Hutchinson, C. R. Insights into the biosynthesis of the benzoquinone ansamycins geldanamycin and herbimycin, obtained by gene sequencing and disruption. Appl. Environ. Microbiol. 71, 4862-4871 (2005).

13 Buchanan, G. O. et al. Production of 8-demethylgeldanamycin and 4,5-epoxy-8demethylgeldanamycin from a recombinant strain of Streptomyces hygroscopicus. J. Nat. Prod. 68, 607-610 (2005).

Supplementary Information accompanies the paper on The Journal of Antibiotics website (http://www.nature.com/ja) 